\title{
DETERMINATION OF HEAVY MACHINES PERFORMANCES BY USING A MEASURING SYSTEM WITH TELEMETRIC SYNCHRONIZATION AND TRANSMISSION OF SIGNALS
}

\author{
Dr Goran Radoičić ${ }^{1 *}$, Dr Miomir Jovanović ${ }^{2}$ \\ 'University "UNION-Nikola Tesla" Belgrade, Faculty of Applied Sciences, Niš, Serbia \\ ${ }^{2}$ University of Niš, Faculty of Mechanical Engineering, Niš, Serbia
}

This paper presents the investigation of importancefor determining the dynamic structural response of heavy lifting machines subjected to extreme external effects. A measuring system for the experimental investigation of the dynamics of heavy lifting machines is proposed.It shows the experimental testing results of carrying structures for several classes of hoisting and an export mining machine. The results refer to the most important dynamic parameters. The dynamic parameters also include the duration of transient phenomena in handling lifting structures and structural damping.A technical solution based on the measuring chain that is integrated into the mining export plant information system was developed in the research. The recommendation to choose optimal measuring equipment for this kind of measurement is given to manufacturers and users on the basis of the experience gained in the design and implementation of specific measuring systems. The technical specification of amplifiers and transducers that should be developed for this kind of measurement is also proposed.

Key words: Dynamics; Lifting; Machine; Measuring; Structure

\section{INTRODUCTION}

Large lifting machines, such as cranes and export mining machinery, are particularly interesting for dynamics research in situations close to incidents, which are often caused by external effects or irregular handling. Experimental testing of these machines is necessary, very complex and risky. Crash tests are not usually the subject of experimental research because of the high cost of this kind of experiment. Therefore, the experience of previous experimental investigations is applied in designing machines. These experiences refer to the values of characteristic dynamic parameters that determine the structure behaviour, and whose applications in mechanical models ensure a faithful simulation of the behaviour without performing an experiment or destroying the structure itself.Experimental investigations into these machines usually have two basic goals: dynamic behaviour analysis under the influence of extreme external effects and verification of dynamic models developed for numerical simulation research purposes. From the research point of view, the legitimate question certainly is: "Is it possible to design a universal measurement system for experimental testing of the characteristic parameters of the largest number of transport machines?" In case of a positive answer one can pose another question: "What should such a measuring kit contain?" In addition to researchers, manufacturers of measuring equipment also want to know this. This paper is a contribution to the answers to the above questions.

\section{STRUCTURE OF THE IMPLEMENTED MEASURING SYSTEMS}

The measurements shown in this paper were carried out on a number of lifting machines according to various scenarios that simulate extreme dynamic effects. On the basis of the performed experiments, the criteria of the design of measuring systems were formulated for determining the most important dynamic parameters in transient operating regimes of cranes, auto-cranes and export mining machines. Figure 1 shows a universal measurement scheme for the measurement of cranes with a mast on the pedestal, boom and tie-rods (e.g. level-luffing and tower cranes).

The largest level-luffing cranes are characterised by great diversity and scope of changes in the measured values, that is: current $100 \mathrm{~A}$, momentum of drive motor $500 \mathrm{Nm}$, deformation 1000 micro-dilatations, suspension force $1000 \mathrm{kN}$, level luffing system force $500 \mathrm{kN}$. The elastic deflections of trails are not large (up to 5-10 $\mathrm{mm}$ ), but the sinking of trails (rails) exceeds $100 \mathrm{~mm}$. Tall level-luffing cranes with the mass of over $400 \mathrm{t}$ are characterised by lowest critical frequencies of vertical vibration (dangerous for overall stability), whose value is $\omega=0.3 \mathrm{~Hz}$, [01]. Tower cranes with heights of up to $25 \mathrm{~m}$ have the incidental frequencies in the range of $\omega=0.5-2$ $\mathrm{Hz},[02]$. The matching of the structural eigenfrequency with the excitation eigenfrequency is called resonance. It leads to an increase in the effect of perturbation, and hence the risk of damage, so this eigenfrequency can be named incidental. An incidental frequency must not only have a resonant value, but may also have other values that lead to large displacement amplitudes (for tall cranes

Faculty of Applied Sciences, 18000 Niš, Serbia, goran.radoicic@gmail.com 


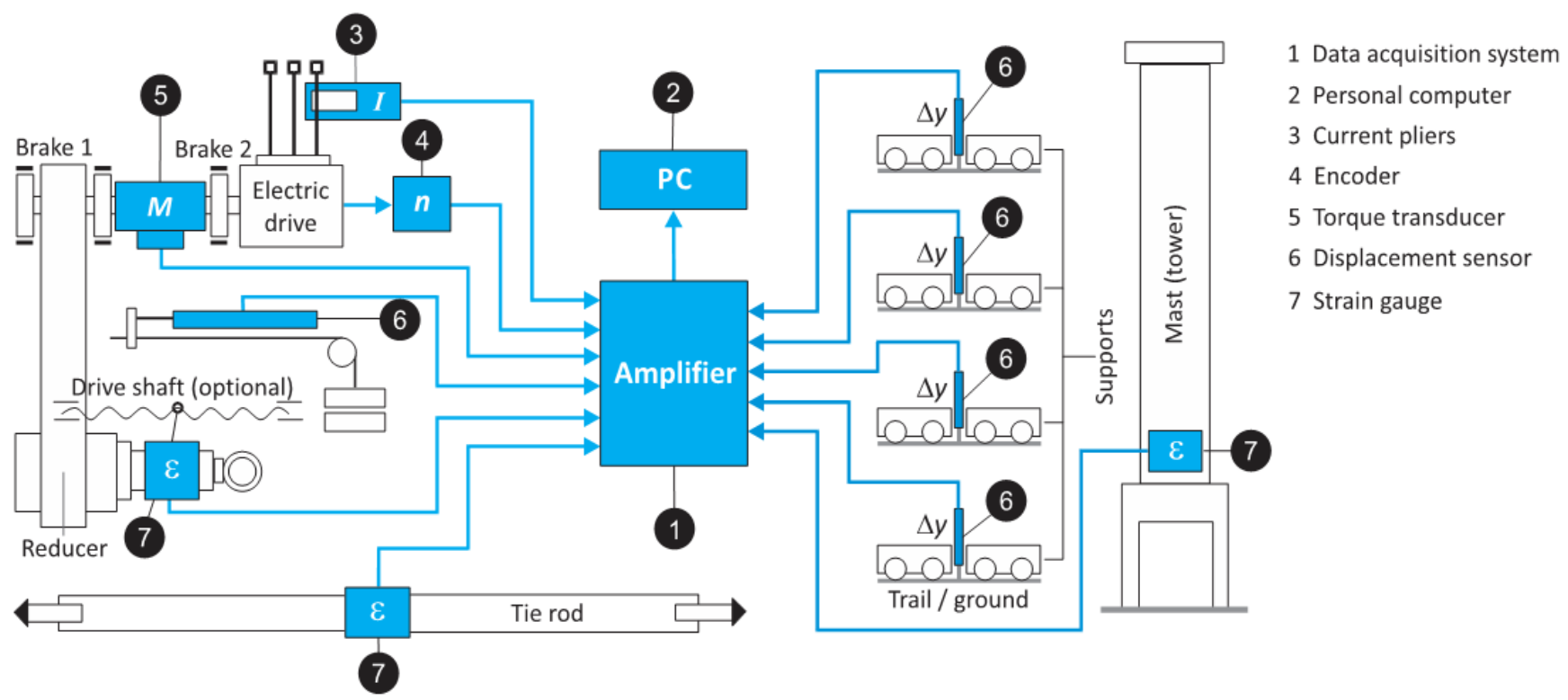

Figure 1: Layout of measuring equipment for measurement of large harbour cranes with a mast on a stand

translations are greater than $1000 \mathrm{~mm}$ ) and structure accelerations (10 $\mathrm{m} / \mathrm{s} 2$ and greater), thereby increasing the risk of damage occurring, [03]. For bridge cranes with the mass of $20 \mathrm{t}$ and the span of $30 \mathrm{~m}$, the incidental eigenfrequency corresponding to the highest amplitudes of oscillation is in the range of $\omega=2.2-2.3 \mathrm{~Hz}$, [04]. For mining stackers, as larger earthmoving machines, the frequency band of the first 100 eigenfrequencies is $\omega=0.07-12.75$ $\mathrm{Hz}$, while the critical eigenfrequencies of resonant vibration in the vertical plane for the main structural parts are in the range of $\omega=2.7-11 \mathrm{~Hz}$, [05].

A typical scheme, which has been in use for several years, is given in Fig. 1, showing the layout of equipment for complex measurement of level-luffing cranes. The experimental research was carried out in the shipyard "Uljanik" Pula, Croatia, [06]. This measuring scheme can be applied in the research of similar large cranes.

Figures 2 and 3 show two universal measurement schemes for the measurement of tower cranes and mobile elevating work platforms (MEWP). The layout of equipment for the measurement of strain-stress states of machines (pos. 3 in Fig. 2 and 5/Fig. 3), force in the hook/rope (4/Fig. 2 and 3/Fig. 3), boom translations under the load (5/Fig. 2), acceleration of the load (6/Fig. 2), and acceleration at the end of the multi-elemental articulated boom (4/Fig. 2) are all shown in Figs. 2 and 3. The greatest practical need is for the dynamic testing of the frame structures that are carried out according to these schemes.

In order to investigate the kinematics and dynamics of the basket and the rope system of large export mining machines, measurements were performed on the machine ASEA HSDE 2.5 (power 1500/2820 kW, lifting speed $4 / 16 \mathrm{~m} / \mathrm{s}$, and capacity $22 \mathrm{t}$ ) used in the service shaft of the Bor Copper Mine, [07,08,09]. The choice of method for signal transmission makes this research specific. Due to the large distance between the measur- ing points (even over $500 \mathrm{~m}$ ), the original measurement system was formed with telemetric synchronization of the measured quantities and transmission of the signals vertically along the mining shaft to the acquisition medium. A technical solution of the electronic measuring system was based on the measuring chain integrated into the export machine information system. The measuring system consisted of universal electronic measuring components that could be adapted to different categories of mines. The plant was experimentally tested at speeds of up to $10 \mathrm{~m} / \mathrm{s}$ and capacities of up to $250 \mathrm{t} / \mathrm{h}$.

This original measuring system is applied to the Koepe towing system, which is now most commonly used for the propulsion of carrying ropes on the principle of adhesion. The system implies the basket for transport of materials on one side of the rope system and counter-weight on the other. The system is balanced by a balancing rope, on the underside, which connects the basket and the counter-weight (Fig. 4). Braking of the system is performed by

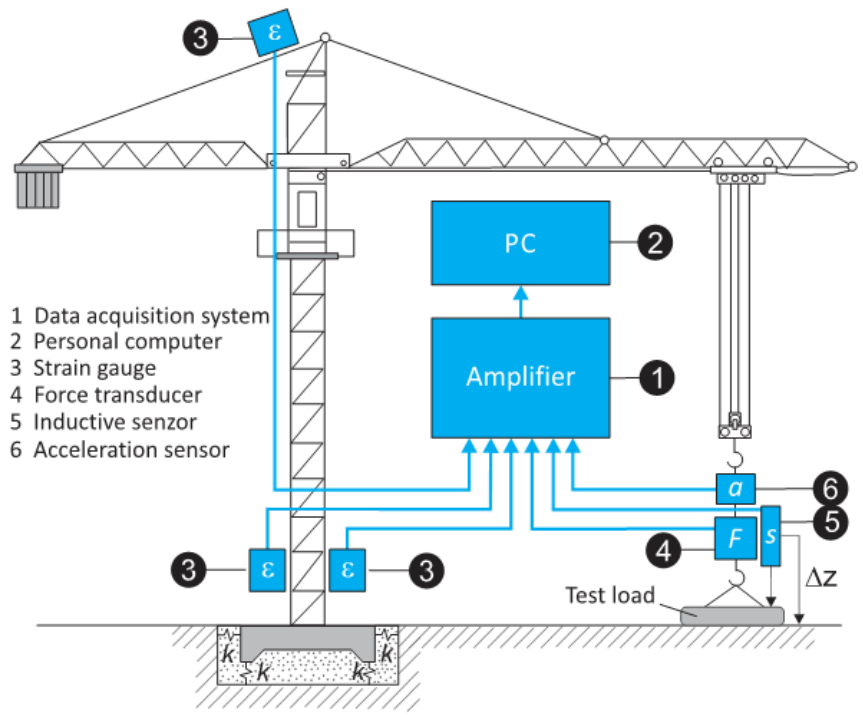

Figure 2: Tower crane - measurement scheme 


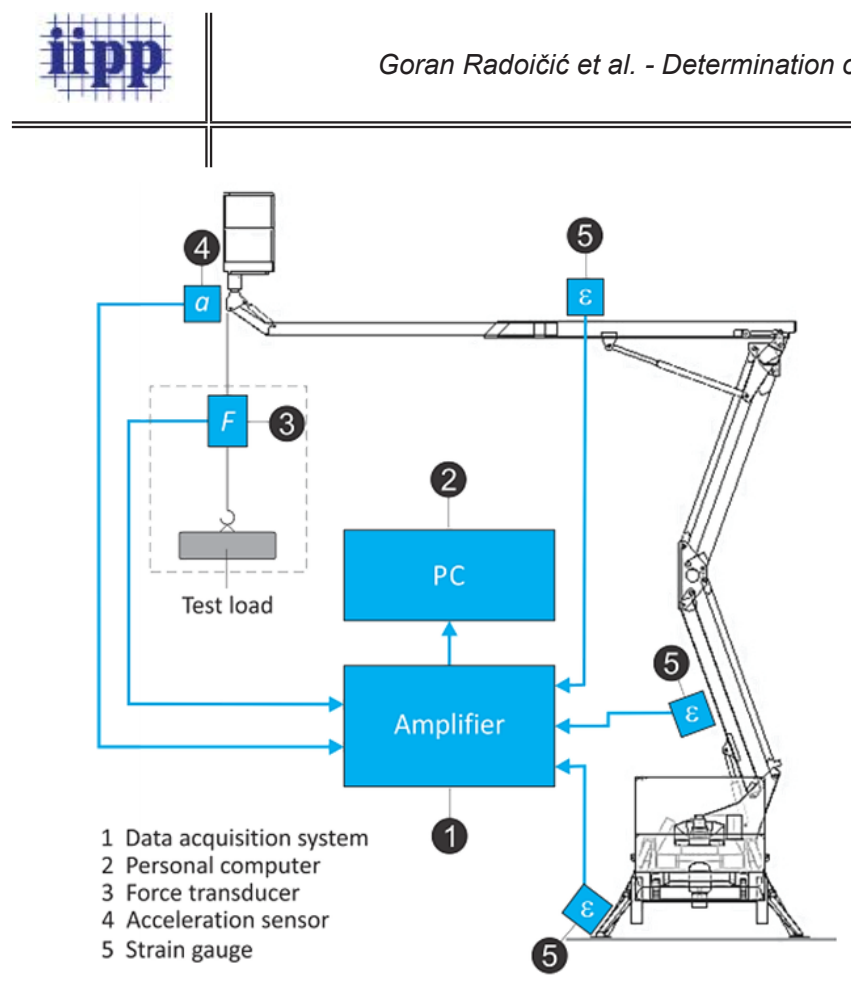

Figure 3: MEWP - measurement scheme

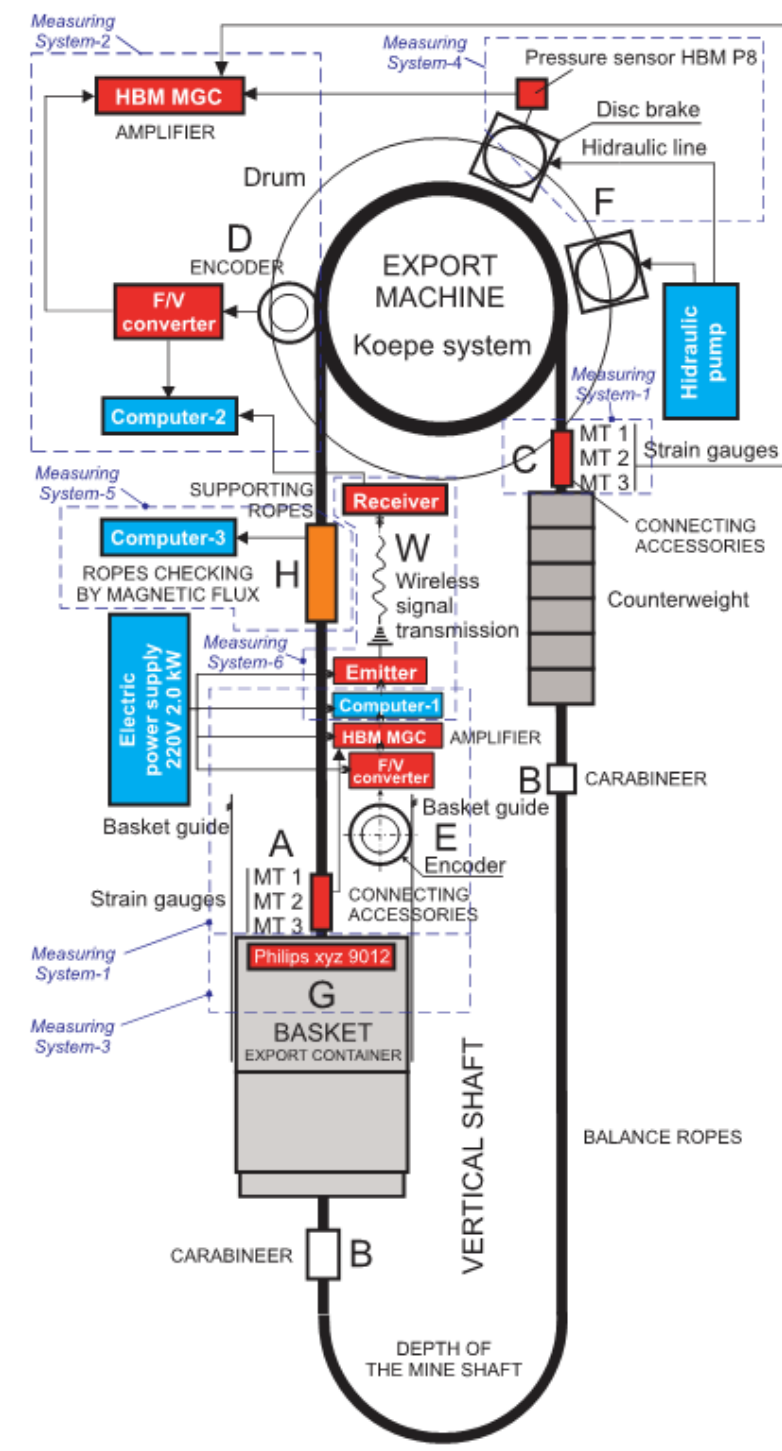

Figure 4: The original measuring and information system on the export mining machine with the Koepe towing principle

hydraulic disc brakes that are mounted directly on the drive drum. The propulsion motors are designed to directly run drive rope pulleys (drum) without speed reduction. An original concept of the technical solution of the measuring and information (communication) system for monitoring export mining machines is shown in Fig. 4.

\section{CABLING PROBLEM IN MEASURING SYSTEMS}

The accuracy of the measurement depends on the quality of the individual components of the measuring chain, namely: transducer, amplifier and connection. The quality of the measurement signal also depends on the transmission mode (cable and wireless). Cabling provides a physical connection between measuring instruments and the device for signal conditioning and data acquisition. Cabling introduces external noise due to the length of the installation, which leads to a weakening of measurement signals. Weak signals have only a few $\mathrm{mV}$. Thus, one of the important criteria for selecting the sensors is the corresponding length of the installation, [10].

A good connectivity of the sensors and amplifiers of measuring signals with a sufficient number of channels for exploring lifting machines indicates a better choice of measuring system. Considering the type of the measured object such as cranes and export mining machines, the measuring equipment requires high flexibility in the conditions of on-site experimental testing. This implies resistance to: moisture, extreme external temperatures, dust, impacts, [10].

According to the recommendation of manufacturers, the best transmission characteristics are displayed by the measuring equipment, primarily cables and connectors, with physically robust design, good contact force and high quality conductor material. Cable lines must use elastic materials to ensure good flexibility. When choosing measuring equipment, special attention should be paid to: insulation resistance or dielectric strength, potential of non-conductive components, projected number of the power on/off switching cycles of the measuring system, and working conditions. When measuring in outdoor conditions, which is generally the case with tests of large cranes and mining machines, it is necessary to use multi-wire cables (e.g., 6-wire) of a wide range of application with low capacitance between the conductors and the insulator, and between the conductors themselves, as well as a high quality protective sheath that provides wire safety from the effects of the environment, while at the same time enables a sufficient flexibility to the cable.

The cabling problem is extremely evident in the measurement of high cranes because of the long cable length, inaccessibility of measurement points, unfavourable environmental conditions, etc. For these reasons, the choice of measuring systems should focus on wireless signal transmission. Measurement systems of large machines in the future should be equipped with transmitting and receiving devices that convert a measured value into a wireless signal and transport it locally (a Wi-Fi 
local network within the measuring system) or globally through the Internet WEB service. A modern system for controlling movement and vibration in large structures under the influence of external loads, includes GPS techniques. This implies that such technology should be an industrially acceptable product from the perspective of wide application and low price.

However, some investigations must be done in a completely different environment. For example, measurements of the dynamic characteristics of mining export machines are performed in a dark and humid environment. For the purpose of such research, where it is impossible to write, a special wireless channel should be provided for the synchronised audio recording of the measurement mode that takes place. In recent years, in addition to the development of sensors for precise work in difficult conditions and modular components, the development of measurement programs which have a good connection with drawing software, database and mathematical analyses is noticeable.

\section{SELECTION OF MEASURING SENSORS AND AMPLIFIERS}

In the experimental research into large lifting machines, priority is given to resistive measuring technology, whose sensors, based on the principle of the strain gauge, have greater durability and duration. Durability is ensured by high-quality material of sensor structure and application of the latest gluing technologies for long-term operation under dynamic load conditions, [11].

For these test models, in particular, tensometric gauges are of interest for the measurement of stress-strain states of cranes and mobile lifting platforms (stress analysis, structural testing). The most commonly used strain gauges have the resistance of $120 \square$ but also larger (in special situations and up to $1 \mathrm{k} \Omega$ ). In the standard experimental application, strain gauges are used for operation in ambient temperatures of up to $150 \mathrm{oC}$. Strain gauges, in similar studies, have the broadest application for measurement of micro-dilations in one direction, and rosettes for measurement in several directions, and most often in the combination of measuring angles of $0 \mathrm{o} / 45 \mathrm{o} / 90 \mathrm{o}$. The strain gauges for measurement of shearing/torsional deformations are also used in practice. The gauges mainly have nickel-plated copper leads with a polyamide carrier. Gauge factor tolerance ranges from $\pm 1.0 \%$ to $\pm 1.5 \%$, depending on the strain gauge carrier length.

For experimental testing of tall structure machines, the force in the rope (ropes) or hook that carries a load is often checked, Fig. 5. This is for the purpose of calculating the dynamic coefficients of the responsible elements of the carrying structure and determining the discharge time after the incident situation which can be caused by the rupture of the rope, the fall of the load or the failure of an element. For such measurements, force transducers with the capacity of $100 \mathrm{kN}$, and in some cases even larger capacities, are most often used. For the purpos- es of permanent monitoring of pressure dynamic forces (e.g. structure weight), sensors such as load cells, force (load) washers and weighing systems are used, [10]. A reliable solution for the force sensor, in large crane tests, should be robust, quick to operate, long-lasting and have the ability to measure the medium pressure force and tensile force of $\pm 100+k N$.

Inductive displacement sensors with the measurement range of $>200 \mathrm{~mm}$ make up an integral part of the universal measuring system of large cranes. Thus, for example, the nominal measuring range of up to $1500 \mathrm{~mm}$ fully corresponds to the needs of measuring the displacement of large cranes and mobile lifting machines. These sensors convert an inductive displacement of the loose core (and compact dimensions) to the appropriate quantity of the output voltage variation of current in $\mathrm{mV} / \mathrm{V}$. A small body length of the sensor in relation to the instrumental measuring range presents a challenge in improving the production of these sensors. Preference is given to converters with a built-in full measuring bridge, based on the principle of differential induction, and with a simple connection to the acquisition device.

Figure 6 shows the photos from the measurement of the displacement (deflection) of the main carrier mid-range of the bridge crane using an inductive sensor, [04]. On this occasion, the sensor HBM W200 was used, but for the measurement of tall or elastic machines one should use the sensors with a larger measuring range. The resistance to environmental phenomena requires these sensors to have a robust structure.

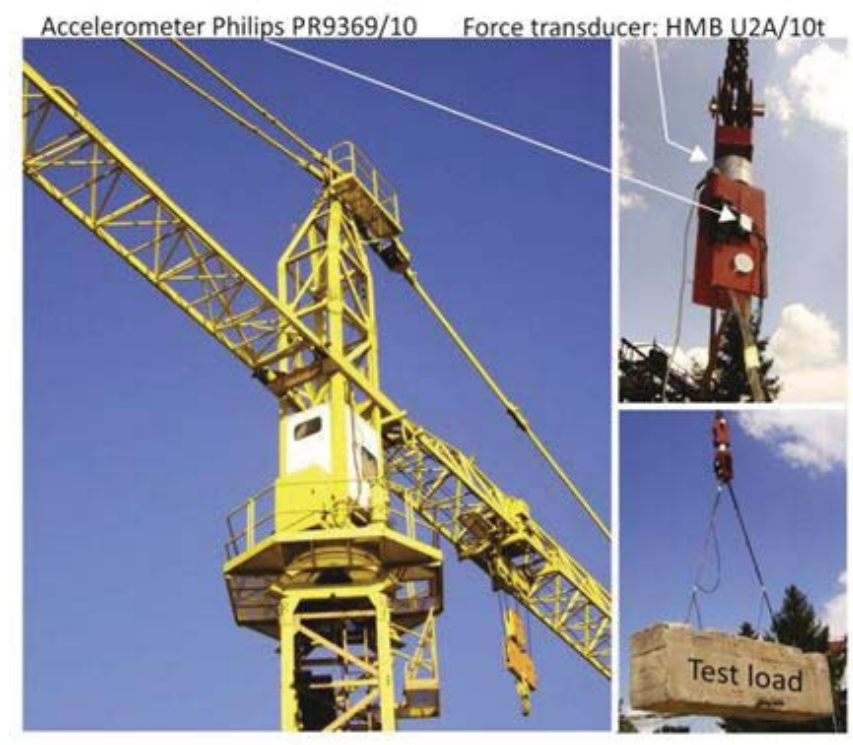

Figure 5: Testing the POTAIN-744E tower crane

Figure 7 shows the positions of strain gauges for the measurement of stress-strain states of the mobile elevating work platform, [12].

In addition to the aforementioned strain gauges, accelerometers and displacement transducers, some measuring systems for structural health monitoring of the bridge structures often use inclinometers to measure the slopes of the main carriers, [13]. 


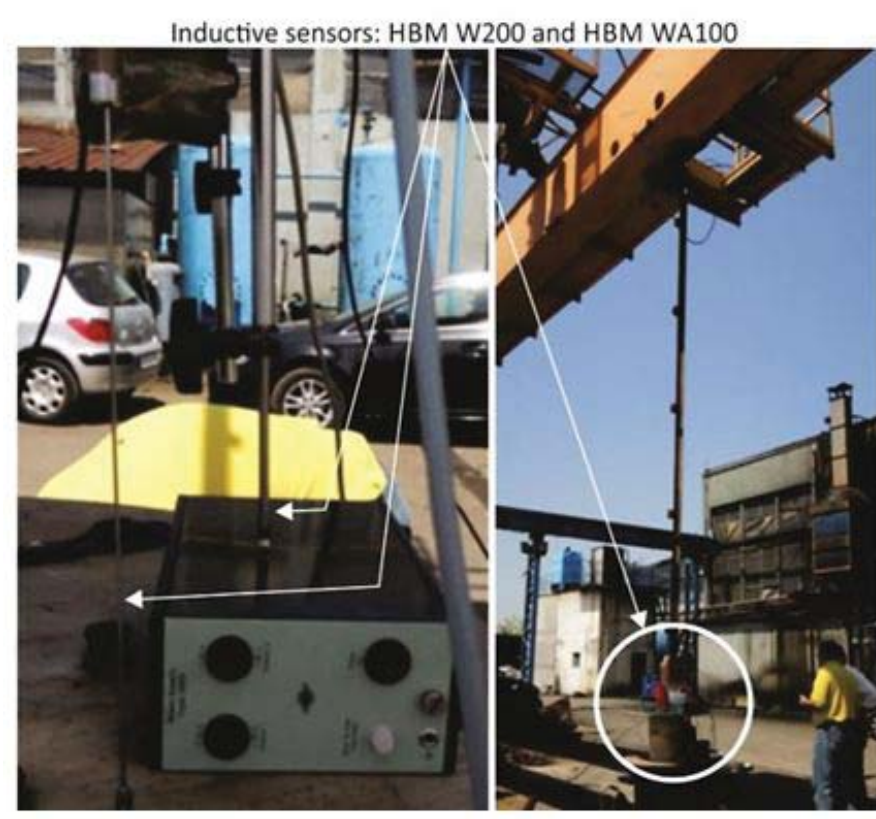

Figure 6: Testing the MIN D-800 bridge crane

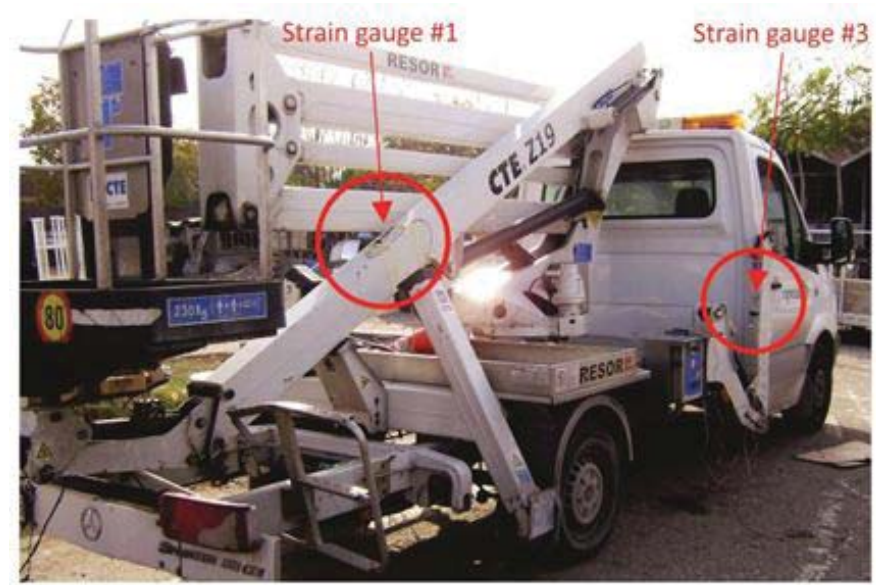

Figure 7: Testing the elevating work platform

The measuring system in Fig. 4, developed for the purpose of experimental investigation on the ASEA HSDE 2.5 export mining machine, consists of six sub-systems for simultaneous measurement of the selected quantities.

Thus, the Measuring System-1 (MS-1) is intended for tensometric measurement of deformations and force in ropes (in the connecting accessories zones $A$ and $C$, Fig. 4). MS-1 is based on the HBM Quantum-X amplifier, HBM LY10/120 and LY 6/120 strain gauges, computer (Computer-1, Fig. 4) and the Catman-AP software. MS-1 is also used for measurement of the basket speed (zone E).

It is mobile and located on the roof of the cabin or basket head. Continuous power supply is provided by the aggregate and UPS.

The Measuring System-2 (MS-2) is used for measurement of the rotating speed of the drum (zone D, Fig. 4). MS-2 consists of the HBM MGC+ (or Quantum-X) amplifier, F/V converter and encoder of 500 pulses per rev- olution, [14]. The HBM Catman-AP software is also use in MS-2. Acquisition and measurement is performed by the computer (Computer-2, Fig. 4) placed directly next to the export machine at the top of the mining shaft, which communicates with the Computer-1 through special peripheral communication components (MS-6).

The Measuring System-3 serves to measure the acceleration of the basket in three directions (zone $\mathrm{G}$ ). For this purpose, the computer on the basket (Computer-1), the HBM Quantum-X amplifier and the acceleration sensor Philips 9369/10 are used.

The Measuring System-4 is designed to measure the pressure in the hydraulic braking installation (zone F). The braking system consists of two disc brakes with a diameter of $3.5 \mathrm{~m}$ with 6 brake disc paws and a control unit. The Computer-2 serves to measure the selected sizes and perform data acquisition.

The Measuring System-5 (MS-5) is used to control the homogeneity and continuity of wires in the ropes (zone $\mathrm{H})$. Control is performed by a measuring device on the principle of magnetic flux. MS- 5 uses a separate computer (Computer-3).

The Measuring System-6 (MS-6) serves to communicate between the two computers (zone W). One of the computers has a communication unit for wireless signal transmission. MS-6 uses the Nano Station Loco NS2L emitter and receiver (Ibiquiti Networks), with the range of up to $5 \mathrm{~km}$ with optical antenna visibility. Using MS-6 one can connect, simultaneously record and synchronise the measured values obtained in other measuring systems from Fig. 4. This allows the monitoring of the basket's vibration during braking or moving at maximum speed. It is possible to register the vibratory delay of the basket from the beginning of braking of the system, curves of momentum, mechanical work on braking and the occurrence of excessive vibrations or incidents.

On the basis of the conditions required to perform experimental investigations into large lifting machines and the schematic measurement displays given in Figs. 1-4, the mandatory technical features of individual appropriate parts of measuring equipment can be specified in the context of the universal measuring system in Table 1.

The technical specifications in Table 1 are proposed based on many years of experience in the design of measuring systems and practical measurement of heavy machines on-site, [06, 15]. These recommendations, in a special way, introduce experiments into the mechanical models of these machines.

All measurements in this paper are directed towards determining the desired dynamic parameters of the selected structures. The testing modes are chosen so as to enable dynamic behaviours similar to extreme situations in machine exploitation. Bearing in mind that the measuring systems were originally designed for the purposes of such research, their application in permanent monitoring of structures requires certain adjustments. The redesign, and thus the development of these measuring systems 
Table 1: Technical specification of required measuring equipment for heavy machines

\begin{tabular}{|c|c|}
\hline $\begin{array}{l}\text { Amplifier: } \\
\text { Nominal measuring range - capacity: } \mathrm{SG} \pm 4 \mathrm{mV} / \mathrm{V} \text {; } \\
\text { Inductive } \pm 100 \mathrm{mV} / \mathrm{N} \\
\text { Principle of measurement: Multi-channel measurement } \\
\text { cards } \\
\text { Material - structure: Combined / } 6 \text { slots minimum } \\
\text { Class of accuracy: } \cup p \text { to } 0.05 \\
\text { Frequency range, vibration resistance DIN EN } 60068: 5 \\
\ldots \\
\text { Temperature conditions: }-20 \ldots+60^{\circ} \mathrm{C} \\
\text { Degree of protection-dirt and moisture (DIN EN 60529): } \\
\text { IP20 } \\
\text { Output signal: }>4 \mathrm{~V} \\
\text { Input voltage: } 85-260 \mathrm{~V} \text { (AC) }\end{array}$ & $\begin{array}{l}\text { Piezoelectric force transducer: } \\
\text { Nominal measuring range }- \text { capacity: } 5 \ldots 120 \mathrm{kN} \\
\text { (only for compressive forces) } \\
\text { Principle of measurement: Piezoelectric principle } \\
\text { Material - structure: Stainless steel housing, robust } \\
\text { design /Quartz (measuring element) } \\
\text { Class of accuracy: Up to } 1 \\
\text { Temperature conditions: }-40 \ldots+120^{\circ} \mathrm{C} \\
\text { Degree of protection-dirt and moisture (DIN EN 60529): } \\
\text { IP65 } \\
\text { Breaking force: } 120 \ldots 400 \% \text { (of } \mathrm{F}_{\text {nom }} \text { ) } \\
\text { Maintenance: Free }\end{array}$ \\
\hline $\begin{array}{l}\text { Force transducer: } \\
\text { Nominal measuring range - capacity: } 0.5 \ldots 200 \mathrm{kN} \\
\text { Principle of measurement: Strain gauge } \\
\text { Material-structure: Stainless steel, robust, hermetic and } \\
\text { laser welded structure } \\
\text { Class of accuracy: Up to } 0.1 \\
\text { Frequency range, vibration resistance DIN EN60068: } \\
5-65 \mathrm{~Hz} \\
\text { Temperature conditions: }-30 \ldots+85^{\circ} \mathrm{C} \\
\text { Degree of protection-dirt and moisture (DIN EN } \\
60529): I P 67 \\
\text { Output signal: } 2 \mathrm{mV} / \mathrm{V} \\
\text { Excitation operating voltage: } 0.5 \ldots 12 \mathrm{~V} \\
\text { Breaking force: }>300 \%\left(\text { of } \mathrm{F}_{\text {nom }} \text { ) }\right. \\
\text { Maintenance: Free }\end{array}$ & $\begin{array}{l}\text { Inductive sensor: } \\
\text { Nominal measuring range - capacity: } 0 \ldots 1500 \mathrm{~mm} \\
\text { Principle of measurement: Differential induction (full } \\
\text { bridge) } \\
\text { Material-structure: Stainless steel, robust, rotating, } \\
\text { mechanical structure } \\
\text { Frequency range, vibration resistance DIN EN60068: } \\
5-65 \mathrm{~Hz} \\
\text { Temperature conditions: }-25 \ldots+80^{\circ} \mathrm{C} \\
\text { Degree of protection-dirt and moisture (DIN EN 60529): } \\
\text { IP67 } \\
\text { Output signal: } 80 \mathrm{mV} / \mathrm{V} \\
\text { Excitation operating voltage: } 0.5 \ldots 10 \mathrm{~V} \\
\text { Max. permissible pressure: } 350 \text { bar } \\
\text { Maintenance: Free }\end{array}$ \\
\hline
\end{tabular}

adapted to structural health monitoring, would move in the direction of the application of practical and effective structural assessment techniques such as damage identification methods, [16], and other similar methods.

Since such monitoring systems for identification of damage in large truss structures, are based on measuring frequency, displacement amplitude, acceleration, the choice of the measuring points is of great importance. Acceleration has to be measured in responsible members of the carrying structure, most often on the pylon, platform, cables or counter-weights. The sensor mounting problem most frequently occurs due to a hardly accessible measuring point. Once mounted sensors are used for a longer period. Major problems occur during the transmission of measuring signals from the analysis device due to the distance of the measuring points from this device. Therefore, in a large number of experimental settings, a need appears for wireless signal transfer, i.e. a wireless system of measuring sensors.

\section{IDENTIFICATION OF SIGNIFICANT DYNAMIC PARAMETERS}

This section of the paper discusses the results of dynamic tests in which a number of significantdynamic pa- rameters of lifting machines in a real environment were determined. The tests identified eigenvalues, displacement amplitudes, forces in the characteristic elements, speeds, accelerations and deformations of the responsible structures elements, unloading time.

Determination of eigenvalues by measurement of microdeformations. For analysing the eigenfrequencies of a MEWP, the preparation of the experiment involves placing the platform with the load in the horizontal position of the maximum reach normally to the longitudinal axis of the vehicle. In this way, we approach the position of the greatest momentum of inertia of the foldable crane mechanism and the lowest eigenvalues. After the forced vibration caused by swinging the platform (by pulling the rope from the ground), the load falls and then the free vibration of the structure occurs until it calms down. Figure 8 shows the diagram of measured deformations of the three strain gauges set on the object according to Fig. 3 , in time $t>175 \mathrm{sec}$, [12]. Multiple dynamic parameters can be determined from the diagram. One of them is the eigenfrequency.

The oscillation period $\mathrm{T}$ is not constant, so its mean experimental value can be determined by observing the free vibration region from Fig. 8 and taking into account the first forty full amplitudes (bold curve). 
The mean value of the oscillation period is calculated as:

$$
\overline{\mathrm{T}_{\text {ex }}}=\frac{1}{\mathrm{n}_{\mathrm{T}}} \sum_{\mathrm{i}=1}^{\mathrm{n}_{\mathrm{T}}=40} \mathrm{~T}_{\mathrm{i}}=0,696 \mathrm{sec}
$$

Based on the obtained value of the oscillation period, the experimental value of the eigenfrequency was calculated: $f_{e x}=1.437 \mathrm{~Hz}$.

\section{Structural damping identification on the basis of logarithmic decrements of vibration}

The applicable structural analysis software (MSC-Nastran and others) introduces structural damping in equations of motion over complex conditions contained in the stiffness matrix, $[17,18]$. The complex matrix of stiffness $\mathrm{K}_{\mathrm{T}}$ is

$$
\mathbf{K}_{\mathrm{T}}=(1+\mathrm{i} \cdot \mathrm{G}) \cdot \mathbf{K}+\mathrm{i} \cdot \sum \mathrm{G}_{\mathrm{E}} \mathbf{K}_{\mathrm{E}}
$$

Where: $i$ is the imaginary number, $G$ is the overall structural damping coefficient, $G_{E}$ is the structural damping coefficient of individual elements, $\mathrm{K}$ is the general stiffness matrix, $K_{E}$ is the stiffness matrix of individual elements.

The conversion of the structural into an equivalent viscous damping, [18] is done by the expression:

$$
\mathbf{C}_{\mathrm{T}}=\mathbf{C}+\frac{\mathrm{G}}{\omega_{3}} \mathbf{K}+\frac{1}{\omega_{4}} \sum \mathrm{G}_{\mathrm{E}} \mathbf{K}_{\mathrm{E}}(3)
$$

Where: $\mathrm{CT}$ is the complex damping matrix, $\mathrm{C}$ is the viscous damping matrix, $\omega_{3}$ and $\omega_{4}$ are the dominant circular eigenfrequencies required in transient analysis.

The structural damping coefficient $\mathrm{G}$ can be determined theoretically and experimentally. The experimental identification of the structural damping was performed by testing onthePOTAIN-744E tower crane (scheme in Fig. 2). The testing regime included lifting and rapidly lowering the test load at the maximum speed to the impact on the

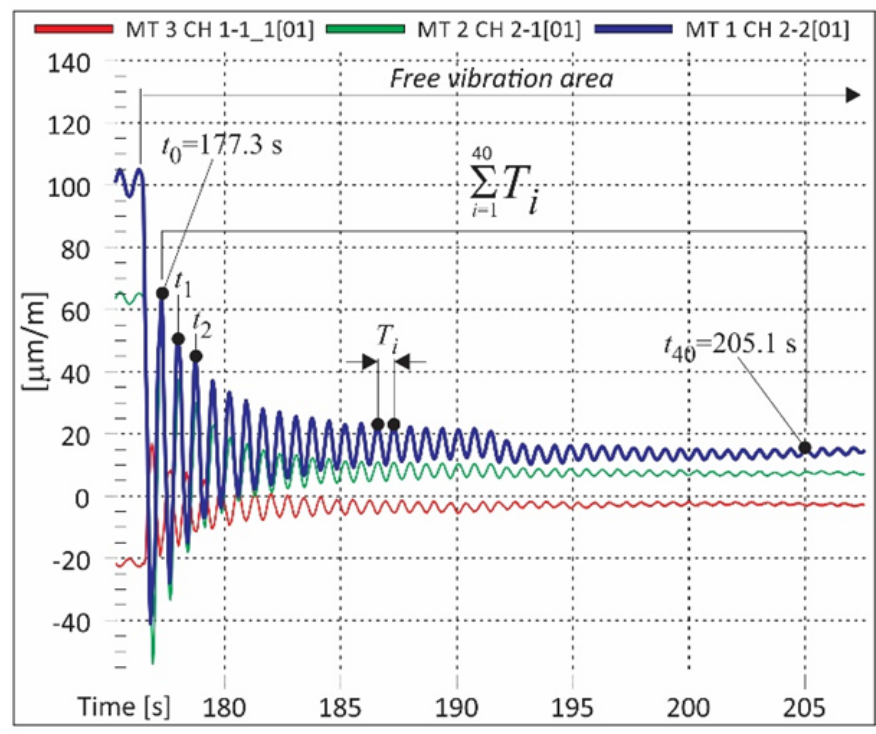

Figure 8: Determination of the mean experimental oscillation period of the CTE-Z19 platform

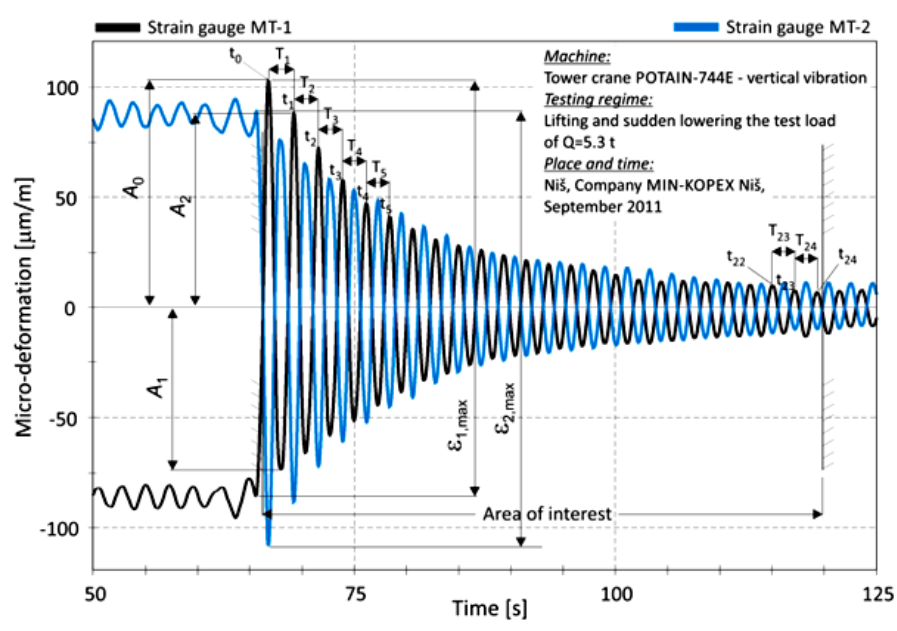

Figure 9: Deformationsof the tower crane in the towerfooter

ground. The testing was carried out using the test load of 2.35 and 5.3 tonnes at reach of 45 and 20.88 metres, respectively.

The descending vibratory motion shown in Fig. 9 is characterised by a variable oscillation period, so the damping coefficient for a sufficient number of decrements and corresponding oscillation periods is required.

The calculation of the individual damping coefficients $\delta_{i}$, considering only the set of the even amplitudes $\left(A_{2}, A_{4}, \ldots\right)$ extended by the initial amplitude $A_{0}$, was performed according to Eq. (4) in which: $A_{2 i}$ is the displacement amplitude, $A_{2(i-1)}$ is the previous same-phase amplitude and $T_{i}$ is the distance between two adjacent amplitudes - the oscillation period.

$$
\delta_{i}=\left(\frac{2 \Delta}{T}\right)_{i}=\left(\frac{\Delta^{\prime}}{T}\right)_{i}=\frac{1}{T_{i}} \ln \frac{\left.\mid A_{2(i} 1\right) \mid}{\left|A_{2 i}\right|} ; i=1,2, \ldots
$$

The mean value of the structural damping coefficient is

$$
\bar{\delta}=\frac{1}{n} \sum_{i=1}^{n} \frac{1}{T_{i}} \ln \frac{A_{2(i-1)}}{A_{2 i}}=0.051 ; n=24
$$

Variance of the statistical set of the coefficients is

$$
\operatorname{Var}(\bar{\delta})=\frac{1}{n-1} \sum_{i=1}^{n}\left(\delta_{i}-\bar{\delta}\right)^{2}=0.000791
$$

\section{Deflection of carrying structure elements}

Dynamic behaviour of highly elastic long-span carrying structures, such as bridge cranes with a track that relies on their own steel pillars, can be risky under the influence of certain perturbation forces. Such testing, Fig. 6, was carried out on the MIN-D800 bridge crane in 2014/2015,[04]. Figure 10 shows the diagram of displacements measured in the vertical direction at the middle of the span of the main structure carrier. The displacements were caused by the force of synchronous bouncing of the two persons who were standing on the carrier. The experiment was employed to show the reality of causing 
damage, with the main carrier derailing from the crane track owing to a relatively small excitation force whose frequency corresponded to the eigenfrequency of the structure (resonance effect). The largest synchronous swinging force of the main carrier was $2.5 \mathrm{~W}_{\mathrm{T}}$, where $\mathrm{W}_{\mathrm{T}}$ is the total weight of two people. For the measurement of displacements in the middle of the crane span the inductive sensor HBM-W200 and WA100, and the Quantum amplifier were used.

The largest double maximum displacement amplitude had a value of $2 A=118 \mathrm{~mm}$. During the measurement, very often there were disturbances caused by the horizontal movement of the core of the measuring instrument, even up to $300 \mathrm{~mm}$, which influenced the shortening of the vertical displacement amplitudes.

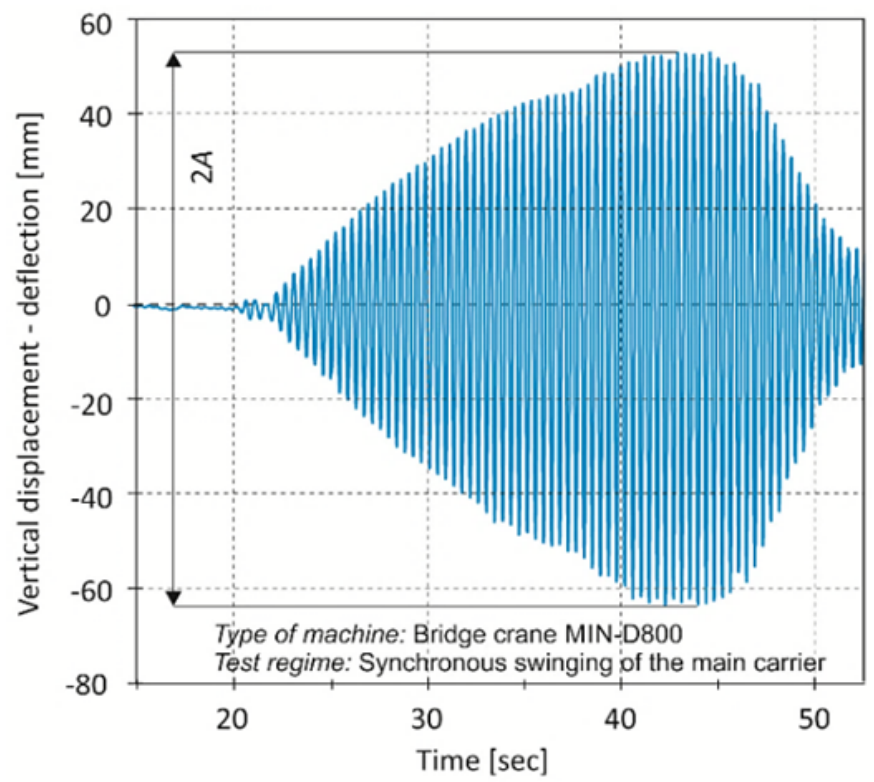

Figure 10: Measurement of the deflection in the middle of the main carrier span

\section{Structure unloading time}

Understanding the two dynamic quantities is essential for investigating incident dynamics and modelling the perturbation force in simulation analvses. These quantities

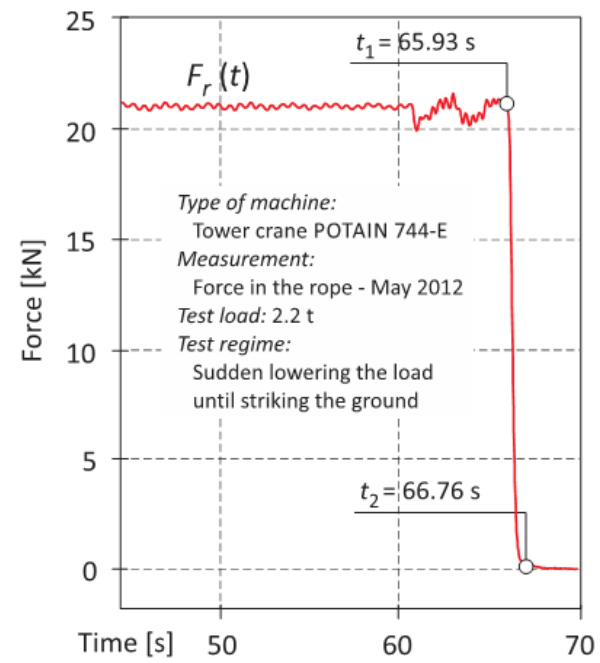

Figure 11: Measurement of the force in the rope are the time of the carrying rope unloading and the time of tie rod unloading. These two quantities are accurately determined experimentally. The "falling" of the load and the failure of the responsible connection elements are often expected events in the operation of lifting machines. Figure 11 shows the measured force on the hook, from which the time of the structure unloading from the action of the load (shock) was obtained, and amounted to $\Delta \mathrm{t} \mathrm{S}=\mathrm{t} 2-\mathrm{t} 1=0.83 \mathrm{~s}$.

The second significant situation is unloading caused by the interruption (fracture) of the connection between the counter-jib tie rod and rest of the crane structure. The crack propagation process is faster in the final fracture phase, so it is possible to determine the time of loss of the counter-jib connection with the rest of the crane structure as time $\Delta \mathrm{t}_{\mathrm{F}}$, which is shorter than the time of load striking the ground $\Delta \mathrm{t}_{\mathrm{s}}$, and according to the research, [02, 03] amounts to $\Delta \mathrm{t}_{\mathrm{F}}=0.6 \mathrm{~s}<\Delta \mathrm{t}_{\mathrm{S}}$.

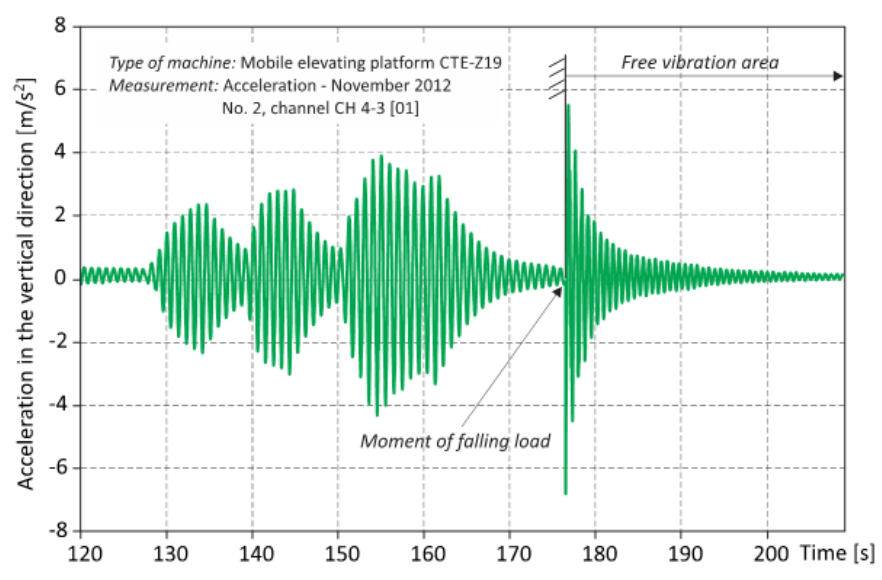

Figure 12: Vertical acceleration of the platform at the lifting height of $4.1 \mathrm{~m}$ and reach of $6.7 \mathrm{~m}$

\section{Acceleration of the structure at unloading}

A different image of the acceleration was obtained from frame structures with an open kinematic chain of manipulator (multi-element boom) in situations of the test load falling from the platform. In the case of the load of 120 $\mathrm{kg}$, the largest structure accelerations in the dominant vertical direction (z-axis) were approximatelly $\pm 0.6 \mathrm{~g}$, Fig. 12. The experimental testing was carried out in 2012 on the CTE-Z19 MEWP, Fig. 7, [12].

\section{Dynamic indicators of export machines}

The dynamic indicators of the ASEA HSDE 2.5 exporting machine were measured in concrete experiments by using the technical solution of the measuring system with Fig. 4. The measurement was carried out in 2015 at the Copper mine Bor. Three performance diagrams obtained by the measurement no. 5-003 are shown in Figs. 13-15, [09].In this measurement, the basket was loaded with the cargo of seven people and measuring equipment. The measurement was performed at the kinematic regime of 


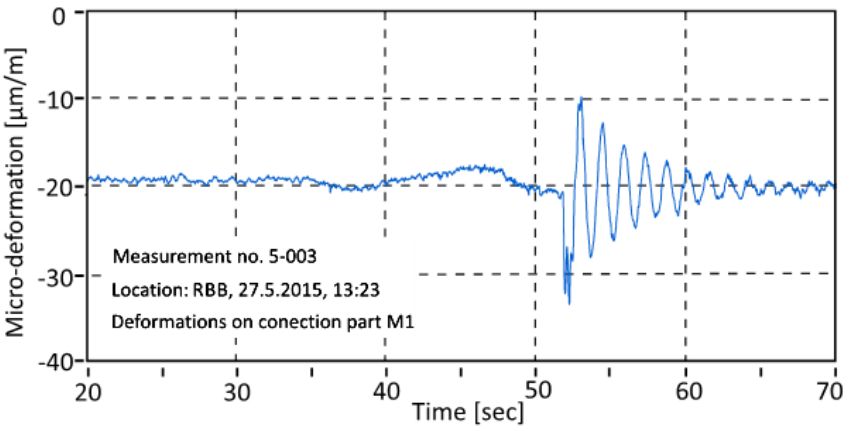

Figure 13: Micro-deformations of one of the elements of the connecting accessories

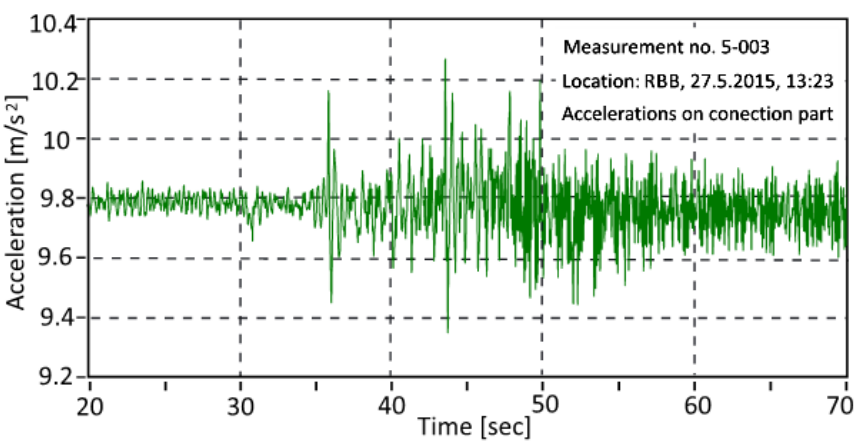

Figure 14: Vertical accelerations of the export machine basket

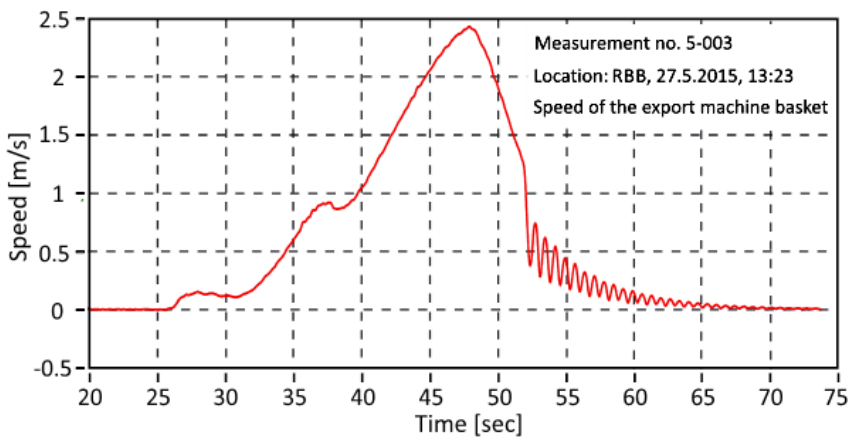

Figure 15: Speed of the export machine basket

upward movement, up to the mean speed of $2.5 \mathrm{~m} / \mathrm{s}$ and an abrupt stop. Vibration had a strong character.

\section{CONCLUSION}

Because of the diversity of experimental studies of large lifting machines, involving a larger number of measuring quantities, there is a need for using a specially designed kit of measuring equipment with the appropriate number and type of measuring channels. Such measuring equipment should be fabricated as a special measurement system whose purpose is precisely the multichannel measurement on different machines. The ease of use is provided by modular Data Acquisition Systems in which the number of desired modules can be selected. Such modules should have their own Central Processing Units, and each measuring channel should have its own Analogue/Digital Unit. This paper defines the specifications of required characteristics of a typical measuring system for heavy machines, which work with loads, as shown in Table 1.

The group of heavy machines that will be the subject of a new improvement in the near future make up the widest used classes of cranes, shipbuilding and level-luffing cranes, tower cranes, industrial stackers and other large mining machinery. As the research requirements for all of these machine classes are similar, the same recommendations for the selection of instruments and devices necessary for carrying out experimental tests should be applied.

A widespread global use of hoisting equipment and an increased risk for the occurrence of incidents, breakdowns and fatal outcomes, lead us to think that one number of measuring devices should be an integral part of the modern equipment. Thus, the users (operators) of these machines could monitor, with a simple appropriate interface in the cabin (or via remote control), the data on the real critical parameters of stability, vibration and displacement. This would mean that measuring devices should not only be employed in research and engineering improvements of the structure of the machine or its systems, but also in the exploitation of machines (on-line monitoring of parameters).

The reaction of such measuring systems to incidental events is actually the response of an intelligent logical structure based on microprocessor control. Their task is to warn the machine operator, through the interface, in the case of an increase or reduction in the observed dynamic parameter in relation to the set or limit value. The on-line contor system, in addition to sensors and transducers, also contains other typical electronic components and microprocessors of a controller for automatic examination of the measured parameters in relation to the limit parameters.

Usingmeasurement technologies gains importance in hazardous technologies and mining plants with vertical shafts. The monitoring of relevant parameters enables an early identification of mechanical changes in responsible elements. This protects both the personnel and the structures.

\section{ACKNOWLEDGE}

The paper is part of the project TR35049 at the University of Niš, Faculty of Mechanical Engineering, supported by the Ministry of Education, Science and Technological Development of the Republic of Serbia.

\section{REFERENCES}

1. Radoičić, G., Jovanović, M. (2017) Transient simulation of impulse wind effect on a tall shipyard frame structure.Journalof Applied Engineering Science, 15(2),192-202,doi:10.5937/jaes15-12935.

2. Radoičić, G., Jovanović, M. (2013). Experimental identification of overall structural damping of system. Strojniški vestnik - Journal of Mechanical Engineering, 59(4), 260-268, doi:10.5545/sv-jme.2012.569. 
3. Radoičić, G., Jovanović, M., Marinković, D. (2014). Nonlinear incidental dynamics of frame structures. Structural Engineering and Mechanics - An International Journal, 52(6), 1193-1208, doi:http://dx.doi. org/10.12989/sem.2014.52.6.1193.

4. Jovanović, M., Radoičić, G., Jovanović, V., Tomić, V., Synchronic excitation - a type of malicious dynamic action, Proceedings of the 21th International Conference on Material Handling, Constructions and Logistics - MHCL'15, held in Vienna, Austria, 23rd -25th September 2015, ISBN 978-86-7083-863-5.

5. Jovanović, M., Radoičić, G., Maneski, T., Dynamical eigenvalue identification of heavy structures machine, Proceedings of the 7th International Conference Heavy Machinery HM 2011, Vrnjačka Banja, Serbia, 29th June - 2nd July 2011, ISBN 978-86-82631-58-3.

6. Jovanović, M., Supporting structure level luffing system and driving mechanisms resistance of portal-jib cranes optimization, Ph.D. Dissertation, University of Niš, Faculty of Mechanical Engineering, Niš, Serbia, 1990.

7. Vladić, J., Jovanović, M., Đokić, R., Kljajin, M., Karakašić, M. (2015) Theoretical and experimental analysis of mine elevator dynamic characteristics. Tehnički vjesnik, 22(4), 1011-1020.

8. Jovanović, M., Tomić, V. (2015) Experimental investigation of mining rope system by magnetic resonance Service window "Vasa Drecun" at the Copper Mine Bor. Research Report, University of Niš, Faculty of Mechanical Enginering, Niš, Serbia.

9. Jovanović, M., Vladić, J., Tomić, V., Đokić R. (2015) Experimental investigation of kinematics and dynamics of the export mining machine ASEA HSDE 2.5 in the Service mine shaft RBB Bor. Research Report, Faculty of Mechanical Enginering, Niš, Serbia.

10. Radoičić, G., Jovanović, M., Arsić, M. (2016) Experience with an on-board weighing system solution for heavy vehicles.ETRI J., 38(4), 787-797, doi:http:// dx.doi.org/10.4218/etrij.16.0115.0183.
11. Schmidt, H., Fatigue analysis of structural adhesive joints under variable amplitude loading, Ph.D. Dissertation, Fraunhofer Institute for Structural Durability and System Reliability, Darmstadt, Germany, 2014.

12. Radoičić, G., Jovanović M., Design of the dynamic models of mobile elevating work platforms and solutions, Proceedings of the 3rd International Conference Mechanical Engineering in XXI Century, held in Niš, Serbia, 17th-18th September 2015,

13. Sousa, H., Cavadas, F., Henriques, A., Bento, J., Figueiras, J. (2013) Bridge defl ection evaluation using strain and rotation measurements. Smart Structures \& Systems, 11(4), 365-386.

14. Arsić, M., Jovanović, M., Radoičić, G., Tomić, V., Marković, D., Technical device solution for kinematics control of mining export machines, Proceedings of the 5th International Conference Transport \& Logistics, held in Niš, Serbia, 5th-6th June 2014, ISBN 978-86-6055-053-0.

15. Radoičić, G., The dynamical behaviour of certain classes of heavy lifting and construction machinery from the aspect of accidental events, Ph.D. Dissertation, University of Niš, Faculty of Mechanical Engineering, Niš, Serbia, 2016.

16. Hornarbakhsh, A., Nagayama, T., Rana, S., Tominaga, T., Hisazumi, K., Kanno, R. (2015) Damage identifi cation of belt conveyor support structure using periodic and isolated local vibration modes. Smart Structures \& Systems, 15(3), 787-806.

17. Gaul, L. (1999) The infl uence of damping on waves and vibrations, Mechanical Systems \& Signal Processing,13(1), 1-30.

18. Rose, T., An approach to properly account for structural damping frequency - dependent stiffness/ damping, and to use complex matrices in transient response, Proceedings of the Worldwide Aerospace Conference and Technology Showcase, held in Toulouse, France, April 2002. 